\title{
Success of promotion strategies for a stroke rehabilitation protocol
}

Danielle Silveira Pires ${ }^{1}$ Danielle De Sá Boasquevisque

Danielli Souza Speciali²

Gisele Sampaio Silva²

Adriana Bastos Conforto ${ }^{2}$

1. University Centre of United Metropolitan Faculties - FMU, São Paulo (SP), Brazil

2. Albert Einstein Israelite Hospital, São Paulo (SP), Brazil

http://dx.doi.org/10.1590/1806-9282.64.05.443

\section{SUMMARY}

OBJECTIVE: To prospectively evaluate the success of promotion strategies for a protocol of motor rehabilitation strategies for patients with stroke at Albert Einstein Hospital.

METHODS: In a clinical trial of neuromodulation and rehabilitation for patients with stroke, conventional methods of dissemination and publications about the research protocol in social networks or on the hospital's website were performed. Frequencies of types of advertisements that reached potentially eligible subjects were calculated.

RESULTS: Data from 80 potentially eligible patients were analyzed. The types of ads that motivated contacts more frequently were social media (38.8\%) and information provided to physicians from other hospitals $(23.8 \%)(p=0,288)$. The frequencies of contacts motivated by publications on the internet (53\%) and conventional strategies (47\%) were similar. Facebook was the digital strategy associated with the higher number of contacts, followed by the hospital's website.

CONCLUSION: Social networks and websites can be as effective as traditional methods of advertisement, in order to reach patients for stroke rehabilitation protocols. These results may have an impact on the planning of clinical trials, including studies that evaluate effects of rehabilitation interventions in patients with stroke.

KEYWORDS: Internet. Social media. Social networking. Neurology. Stroke. Physical therapy modalities.

\section{INTRODUCTION}

Epidemiological studies have revealed an incidence of cerebrovascular accidents (CVA) of 105.4/100,000 inhabitants/year in Joinville, Santa Catarina and 137/100,000 in Matão, in the interior of São Paulo., 2 In a study carried out in Fortaleza, $72.3 \%$ of the patients hospitalized for stroke showed functional dependence defined by a score higher than 2 in the modified Rankin Scale, at the time of discharge. $^{3}$ In Matão, one year after a first stroke, $61 \%$ of the survivors presented some degree of func- tional dependence, defined by a score lower than 100 in the Barthel Index. ${ }^{1}$ The individual and social burden of strokes are expected to grow even more in the coming decades, due to the increased life expectancy and decreased mortality in the acute phase of the disease. $^{4,5}$

Therefore, rehabilitation strategies aimed at the reduction of disability in stroke victims should be developed in parallel with efforts in prevention and emergency treatment. The recruitment of patients is a substantial challenge for trials in general ${ }^{6}$ and for

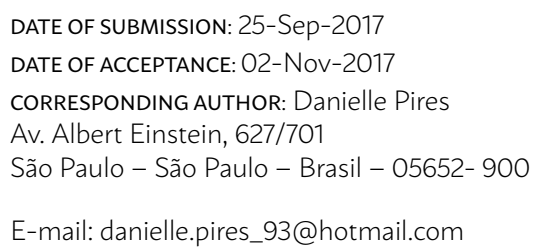


rehabilitation in particular.-12 An alternative to improve recruitment is the use of social networks for the promotion of research projects.

From 2000 until 2008, there was a growth of around $342 \%$ in access to the internet and there are estimates that over 1.5 billion people, or $23.8 \%$ of the world population, use it in their daily lives. ${ }^{13}$

The use of digital media and social networks for participant recruitment in research protocols was identified in studies on the health of children, adolescents, ${ }^{14,15}$ and pregnant women, ${ }^{16,17}$ as well as in projects for smoking cessation, ${ }^{18,19}$ promotion of physical activity, ${ }^{20,}{ }^{21}$ assessment of the relationship between cognitive function and diabetes mellitus, ${ }^{22}$ or in clinical trials on osteoporosis ${ }^{23}$ and breast cancer. ${ }^{24} \mathrm{We}$ did not identify the use of these tools in studies on the rehabilitation of stroke patients, a condition with high individual, social and economic impact worldwide.

In Brazil, we identified only two studies that described the effectiveness of different promotion strategies for research in rehabilitation aimed to stroke patients with stroke. ${ }^{9,} 10$ Only one of them ${ }^{9}$ reported the use of electronic brochures on hospital websites. Social networks were not used as communication tools in these projects.

\section{OBJECTIVES}

The objectives of this study were: to assess the success of promotion strategies that involve the use of digital media and social networks for patients with cerebrovascular diseases, in a rehabilitation protocol in progress at the Hospital Israelita Albert Einstein; to compare the success of conventional promotion strategies with publications in social networks and the hospital website.

\section{METHODOLOGY}

\section{Study design}

We prospectively assessed the recruiting strategies for the study "Safety of transcranial stimulation by a continuous current in the subacute phase after an ischemic cerebrovascular accident". This project consisted of a randomized clinical trial on transcranial direct current stimulation (tDCS) applied in the subacute phase (72 hours at 6 weeks) in patients with paresis of the upper limb after an ischemic cerebrovascular accident (stroke). This type of intervention has been used in studies with the objective of potentiating the effects of rehabilitation. ${ }^{25,26}$ The clinical trial was approved by the Research Ethics Committee of the Hospital Israelita Albert Einstein (HIAE) in April 2015, registered in the website Clinicaltrials. gov (NCT024555427) and is currently ongoing. This project was exempted from approval of the Research Ethics Committee of the HIAE because it aims at improving processes.

The criteria for inclusion in the study are: age between 18 and 80 years; ischemic stroke of any etiology occurred between 72 hours and 6 weeks before the start of the protocol, leading to unilateral paresis of the upper limb, measured by the stroke scale of the National Institutes of Health (minimum of 1 in item 5 a or item $5 b$; maximum score on the scale between 5 and 15); ${ }^{27}$ informed consent in writing, as a specific term; radiological confirmation of the ischemic stroke by structural magnetic resonance or computed tomography of the skull without contrast.

The criteria for exclusion criteria were: other neurological diseases prior to the ischemic stroke (with the except of migraines); a history of seizures, psychiatric disorders; advanced systemic disease, such as cancer in advanced stage or kidney disease, clinical and/or hemodynamic instability; contraindication to physiotherapy; presence of pacemaker, uncontrolled arrhythmias or decompensated heart disease; score on the modified Rankin Scale ${ }^{27}$ greater than 2 before the ischemic stroke; dementia reported by the patient and/or by a companion, such as loss of memory prior to the event and at least one other cognitive domain, with social or occupational harm; ${ }^{28}$ pregnancy; aphasia in understanding; prior ischemic stroke compromising the corticospinal pathway in the unaffected hemisphere.

\section{PROMOTION}

Five promotion methods were used to recruit research voluntaries:

- Printed signs posted on communication boards and on the intranet accessed by HIAE employees.

- Emails e-mails sent to physicians, physical therapists and researchers from the HIAE, as well as for the Integrated Program of Neurology;

- Emails sent to doctors and researchers external to the HIAE;

- publications of research promotion in social networks (Facebook, LinkedIn, Twitter); 
Publications in the HIAE site through the links:

- http://www.einstein.br/Pages/Home.aspx,

- http://medicalsuite.einstein.br/Paginas/home. aspx) and http://medicalsuite.einstein.br/ pesquisa/Paginas/.

During the promotion, the primary requirements for the candidate to participate were informed: Ischemic stroke and paresis in one hand. In case of interest, the patient or their family/guardian should contact the research team of the hospital via email or telephone to verify other inclusion and exclusion criteria.

Between October 07, 2015 and September 09, 2016, five promotion attempts were made by means of printed signs displayed at the internal employee communication boards of HIAE, four by emails to physicians and researchers from the HIAE, another four by emails to physicians and researchers from other hospitals, in addition to a permanent posting on the HIAE website, three on the LinkedIn page, two on the institutional profile on Twitter and six on the HIAE page on Facebook. In one of the Facebook posts, the target audience was segmented according to place of residence, age, educational level and interests. The other five publications were made in the traditional way, without segmentation.

The promotion methods by which patients were made aware of the project were stored in a database in Excel, version 2010.

The emails sent to internal and external doctors, physiotherapists and researchers and the printed signs posted on boards were classified as conventional promotion methods.

\section{STATISTICAL ANALYSIS}

For the characterization of patients, the mean age and standard deviation were calculated, as well as the percentage of male and female individuals. In addition, the proportions on the degree of relationship between the patient and the individual who contacted the research team were calculated.

The binomial test was used to test the equality of the proportion of digital and non-digital contact occurrences. The analysis was performed with SPSS (version 24), considering a significance level of 5\%.

\section{RESULTS}

In total, 88 individuals contacted the research team. For eight of them, it was not possible to de- fine how the individuals became aware of the project. For this reason, we analyzed data from 80 individuals (40 men). The mean age ( \pm standard deviation) was $55 \pm 17$ years $(p=0.115)$. In the majority of cases (79.6\%), it was not the patient who contacted the research team, but a relative.

The most frequent means of promotion that motivated contact (Table 1) were social networks and information supplied by external doctors. Forty-three individuals $(53.8 \%)$ were reached by posts about the project in social networks or on the HIAE website, and 37 by conventional methods (47\%). There was no statistically significant difference between the scope of both methods of promotion ( $p=0.288$ ).

In relation to online publications, Facebook promotion was the most effective (29/43; $67.4 \%$ of all contacts), followed by the HIAE website $(12 / 43 ; 27.9 \%)$, Twitter (1/43; 2.3\%) and LinkedIn (1/43; 2.3\%). The impact of the directed posting on Facebook was more significant than the traditional ones. On average, each conventional post via Facebook was responsible for the contact of four individuals (13.7\%), while the post directed at specific segments reached nine, 31\% of the total number of people informed about the research through this social network.

So far, 12 patients were included in the project. Of these, five (41.7\%) were made aware of the research by physicians outside the HIAE, two (16.7\%) by printed signs, two (16.7\%) by internal HIAE doctors, two (16.7\%) by Facebook and one (8.3\%) by Twitter.

\section{DISCUSSION}

The main result of this research is that little more than half of the individuals who contacted the research team to receive information or participate in the project were reached by online publications (Facebook, Twitter, LinkedIn, and HIAE website). To this moment, this is the first study to demonstrate

TABLE 1. PROMOTION METHODS THAT LED TO CONTACT WITH THE RESEARCH TEAM.

\begin{tabular}{l|l|l} 
Promotion methods & $\mathrm{n}$ & $\%$ \\
\hline Social networks. & 31 & 38.8 \\
\hline HIAE website & 12 & 15.0 \\
\hline Internal doctor (emails) & 6 & 7.5 \\
\hline External doctor (emails) & 19 & 23.8 \\
\hline Signs on employee communication boards & 12 & 15.0 \\
\hline Total & 80 & 100 \\
\hline
\end{tabular}

Notes: $(n=$ number, $\%$ = percentage). HIAE: Hospital Israelita Albert Einstein 
the role of this form of communication in the recruitment of participants for a clinical trial on rehabilitation. Most participants, however, received information from their physicians. It is possible that health professionals promoted the protocol to individuals with higher potential of eligibility, rather than lay individuals informed about the research by social networks. Even so, both conventional methods of communication and postings on social networks have contributed to the inclusion of participants.

In Brazilian studies on rehabilitation that detailed the recruitment of patients, different strategies were used. In a research on the use of neuromodulation combined with physical therapy in the first weeks after a stroke, the protocol was individually presented to patients treated in the acute phase in a tertiary hospital. ${ }^{10}$ In another study focused on the effects of motor training up to six months after a stroke, the promotion was done by means of leaflets distributed in public places, electronic brochures distributed in non-governmental organizations or hospital websites, communication with neurologists who worked in private clinics, physical therapists who worked in rehabilitation clinics or hospitals, and other researchers. ${ }^{9}$ The most successful strategy was the referencing by physical therapists responsible for the patients' hospital treatment (75\%). Electronic Brochures motivated contact with researchers in only $1 \%$ of the cases. Other digital forms of research promotion were not used.

In other studies, $15 \%$ to $100 \%$ of the individuals who sought information about research protocols were reached by publications on websites. In addition, between $9 \%$ and $91 \%$ of the individuals included were reached by these promotion methods. ${ }^{14,18-20,22}$ In some studies, in fact, the promotion was done exclusively on social networks. ${ }^{15-17}$

Therefore, our results and those of other authors indicate that the online publication of protocol information can contribute to the reaching of potentially eligible individuals. The promotion on Facebook through segmented profiles was more effective than the traditional posting in this social network, according to our data and in line with what was reported by other authors. ${ }^{29}$ Therefore, targeting ads to specific audiences can facilitate the recruitment of participants.

In almost $80 \%$ of the cases, the individuals who contacted the HIAE researchers were not the individuals who had suffered a stroke, but a relative. This result was expected, considering that the neurologi- cal deficits may impair the ability of communication between patients and researchers, as well as the patient's access to the means of research promotion.

This study presents some limitations. The mean age of patients potentially eligible was lower than the ones described in epidemiological studies of population or hospital database in Brazil. ${ }^{1-3}$ However, the ages of the individuals who contacted the researchers were not recorded. According to a survey conducted by the ComScore website in 2014, in the United States, the average age of social network users is 25-34 years (Facebook and Twitter) and 35-44 years (LinkedIn). ${ }^{30}$ We do not know whether individuals of these age groups predominated among those who contacted the researchers by digital means or otherwise. In the same way, we cannot conclude whether there is a relationship between the age of these individuals and the lower mean age of the patients who motivated the contact.

\section{CONCLUSION}

Online postings can be as useful for the promotion of a research protocol on rehabilitation as conventional strategies, such as the use of posted signs or sending emails to health professionals. The communication with health professionals can facilitate the recruitment of individuals with a higher probability of eligibility than the promotion on social networks, but both traditional methods and online postings can contribute to the inclusion of participants. These results may have an impact on the planning of clinical trials on the effects of rehabilitation interventions in individuals with cerebral vascular accidents and of research projects in general, in places where access to social networks or hospital websites is part of the everyday life of the population.

\section{ACKNOWLEDGMENTS}

We thank the nurses Alda Fernandes de Castro and Karina Fernandes Days for the aid in the recruitment of patients. The board of trade and marketing of HIAE for participating in the promotion of the project. The Integrated Program of Neurology, for supporting the project.

Conflicting interests: Author 1 was granted a Scientific Initiation funding, by the Uniemp Institute, in the amount of $\mathrm{R} \$ \mathbf{5 7 9 . 3 0}$ for the period from October 1st, 2015 to December 31st, 2016. 


\section{RESUMO}

OBJETIVO: Avaliar prospectivamente o sucesso de estratégias de divulgação de um protocolo de reabilitação motora para indivíduos com doenças cerebrovasculares no Hospital Israelita Albert Einstein (HIAE).

MÉTODOS: Um ensaio clínico de neuromodulação e reabilitação para indivíduos com acidente vascular cerebral (AVC) e paresia do membro superior utilizou meios de divulgação digitais e meios tradicionais, não digitais. Foram calculadas frequências das modalidades de divulgação que alcançaram indivíduos potencialmente elegiveis para o protocolo.

RESULTADOS: Foram analisados dados de 80 indivíduos que manifestaram interesse em participar da pesquisa. As formas de divulgação mais frequentes que motivaram o contato foram redes sociais (38,8\%) e informações fornecidas a médicos externos ao HIAE (23,8\%). As frequências de contatos motivados por publicações na internet (53\%) foram semelhantes às de contatos motivados por divulgações convencionais (47\%) ( $p=0,288)$. Em relação às publicações sobre a pesquisa na internet, a divulgação pelo Facebook foi a mais eficiente, seguida pelo site do HIAE.

CONCLUSÃO: A divulgação de um protocolo de pesquisa em reabilitação por meio de publicações em redes sociais e sites pode ser tão eficaz quanto estratégias convencionais de comunicação. Estes resultados podem ter impacto no planejamento de ensaios clínicos, incluindo os que têm por objetivo avaliar efeitos de intervenções de reabilitação em indivíduos com AVC.

PALAVRAS-CHAVE: Internet. Mídias sociais. Rede social. Neurologia. Acidente vascular cerebral. Modalidades de fisioterapia.

\section{REFERENCES}

1. Minelli C, Fen LF, Minelli DP. Stroke incidence, prognosis, 30-day, and 1-year case fatality rates in Matão, Brazil: a population-based prospective study. Stroke. 2007;38(11):2906-11.

2. Cabral NL, Gonçalves AR, Longo AL, Moro CH, Costa G, Amaral CH, et al. Incidence of stroke subtypes, prognosis and prevalence of risk factors in Joinville, Brazil: a 2 year community based study. J Neurol Neurosurg Psychiatry. 2009;80(7):755-61.

3. Carvalho JJ, Alves MB, Viana GÁ, Machado CB, Santos BF, Kanamura AH, et al. Stroke epidemiology, patterns of management, and outcomes in Fortaleza, Brazil: a hospital-based multicenter prospective study. Stroke. 2011;42(12):3341-6.

4. Feigin VL, Roth GA, Naghavi M, Parmar P, Krishnamurthi R, Chugh S, et al; Global Burden of Diseases, Injuries and Risk Factors Study 2013 and Stroke Experts Writing Group. Global burden of stroke and risk factors in 188 countries, during 1990-2013: a systematic analysis for the Global Burden of Disease Study 2013. Lancet Neurol. 2016;15(9):913-24.

5. Kaup AO, Santos BF, Victor ES, Cypriano AS, Lottenberg CL, Cendoroglo Neto $M$, et al. Georeferencing deaths from stroke in São Paulo: an intra-city stroke belt? Int J Stroke. 2015;10(Suppl A100):69-74.

6. Alexandrov AV. Slow recruitment in clinical trials: failure is not an option! Int J Stroke. 2006;1(3):160.

7. Blanton S, Morris DM, Prettyman MG, McCulloch K, Redmond S, Light $\mathrm{KE}$, et al. Lessons learned in participant recruitment and retention: the EXCITE trial. Phys Ther. 2006;86(11):1520-33.

8. Lloyd G, Dean CM, Ada L. Issues in recruiting community-dwelling stroke survivors to clinical trials: the AMBULATE trial. Contemp Clinl Trials. 2010;31(4):289-92.

3. Scianni A, Teixeira-Salmela LF, Ada L. Challenges in recruitment, attendance and adherence of acute stroke survivors to a randomized trial in Brazil: a feasibility study. Rev Bras Fisioter. 2012;16(1):40-5.

9. Anjos SM, Cohen LG, Sterr A, Andrade KN, Conforto AB. Translational neurorehabilitation research in the third world: what barriers to trial participation can teach us. Stroke. 2014;45(5):1495-7.

10. Potter-Baker KA, Bonnett CE, Chabra P, Roelle S, Varnerin N, Cunningham DA, et al. A game of hide and seek: is it possible to recruit more patients for NIBS studies in stroke? J Neurol Sci. 2015;358(1-2):472-4.

11. Potter-Baker KA, Bonnett CE, Chabra P, Roelle S, Varnerin N, Cunningham DA, et al. Challenges in recruitment for the study of noninvasive brain stimulation in stroke: lessons from deep brain stimulation. I Stroke Cerebrovasc Dis. 2016;25(4):927-37.

12. Couper M. Web surveys: a review of issues and approaches. Public Opin Q. 2000;64(4):464-94.

13. Close S, Smaldone A, Fennoy I, Reame N, Grey M. Using information technology and social networking for recruitment of research participants: experience from an exploratory study of pediatric Klinefelter syndrome. I Med Internet Res. 2013;19;15(3):e48.

14. Fenner Y, Garland SM, Moore EE, Jayasinghe Y, Fletcher A, Tabrizi SN, et al. Web-based recruiting for health research using a social networking site: an exploratory study. | Med Internet Res. 2012;14(1):e20.
15. O'Connor A, Jackson L, Goldsmith L, Skirton H. Can I get a retweet please? Health research recruitment and the Twittersphere. J Adv Nurs. 2014;70(3):599-609.

16. Arcia A. Facebook advertisements for inexpensive participant recruitment among women in early pregnancy. Health Educ Behav. 2014;41(3):237-41.

17. Gordon JS, Akers L, Severson HH, Danaher BG, Boles SM. Successful participant recruitment strategies for an online smokeless tobacco cessation program. Nicotine Tob Res. 2006;8(Suppl 1):S35-41.

18. Graham AL, Milner P, Saul JE, Pfaff L. Online advertising as a public health and recruitment tool: comparison of different media campaigns to increase demand for smoking cessation interventions. J Med Internet Res. 2008;10(5):e50.

19. Jones L, Saksvig BI, Grieser M, Young DR. Recruiting adolescent girls into a follow-up study: benefits of using a social networking website. Contemp Clin Trials. 2012;33(2):268-72.

20. Partridge SR, Balestracci K, Wong AT, Hebden L, McGeechan K, Denney-Wilson $E$, et al. Effective strategies to recruit young adults into the TXT2BFiT mHealth randomized controlled trial for weight gain prevention. JMIR Res Protoc. 2015;4(2):e66.

21. Peñaherrera $C A$, Palacios $M$, Duarte $M C$, Santibáñez $R$, Tamariz $L$, Palacio A. Use of media for recruiting clinical research volunteers in Ecuador. Medwave. 2015;15(11):e6334.

22. Heard A, March R, Maguire P, Reilly P, Helmore J, Cameron S, et al. Recruitment strategies for an osteoporosis clinical trial: analysis of effectiveness. Australas J Ageing. 2012;31(3):176-80.

23. Rimel B|, Lester |, Sabacan L, Park D, Bresee C, Dang C, et al. A novel clinical trial recruitment strategy for women's cancer. Gynecol Oncol. 2015;138(2):445-8.

24. Elsner B, Kugler J, Pohl M, Mehrholz J. Transcranial direct current stimulation (tDCS) for improving activities of daily living, and physical and cognitive functioning, in people after stroke. Cochrane Database Syst Rev. 2016;3:CD009645.

25. Liew SL, Santarnecchi E, Buch ER, Cohen LG. Non-invasive brain stimulation in neurorehabilitation: local and distant effects for motor recovery. Front Hum Neurosci. 2014;8:378.

26. Cincura $C$, Pontes-Neto OM, Neville IS, Mendes HF, Menezes DF, Mariano DC, et al. Validation of the National Institutes of Health Stroke Scale, modified Rankin Scale and Barthel Index in Brazil: the role of cultural adaptation and structured interviewing. Cerebrovasc Dis. 2009;27(2):119-22.

27. Galvin JE, Sadowsky CH; NINCDS-ADRDA. Practical guidelines for the recognition and diagnosis of dementia. I Am Board Fam Med. 2012;25(3):367-82.

28. Remschmidt C, Walter $D$, Schmich $P$, Wetzstein M, Deleré $Y$, Wichmann O. Knowledge, attitude, and uptake related to human papillomavirus vaccination among young women in Germany recruited via a social media site. Hum Vaccin Immunother. 2014;10(9):2527-35

29. IFD Comunicação [sítio na Internet.] São Paulo: Agência de publicidade; 2015 [cited 2016-9-2] Available from: http://www.ifd.com.br/marketing/ qual-a-faixa-etaria-mais-presente-nas-principais-redes-sociais. 